\title{
EFFECT OF OXYMATRINE ON TRICLOSAN-INDUCED OVARIAN TOXICITY IN FEMALE RATS.
}

\author{
By \\ Ali $\mathrm{NE}^{1}$, Abd El kareem $\mathrm{HM}^{2}$, Elnoury $\mathrm{HA}^{3}$, Shalaby $\mathrm{NM}^{4}$ and Mahmoud $\mathrm{AR}^{4}$ \\ ${ }^{1}$ Department of Forensic Medicine and Clinical Toxicology, ${ }^{2}$ Department of Medical Biochemistry and \\ Molecular Biology, ${ }^{3}$ Department of Pharmacology, Faculty of Medicine, Benha University, Benha, \\ ${ }^{4}$ Department of Forensic Medicine and Clinical Toxicology, Faculty of Medicine,
}

Zagazig University, Zagazig, Egypt

Corresponding author: Ali NE.Email: NAGEH.ALI@fmed.bu.edu.eg

Submit Date: 2020-12-22

Revise Date: 2021-01-18

Accept Date: 2021-01-21

DOI:10.21608/ejom.2021.50318.1217

Authors' contribution: Authors contributed equally to this work + Dr Ali NE was responsible for editing.

\begin{abstract}
Introduction: Triclosan [TCS] is a broad-spectrum antibacterial xenoestrogen commonly used in cosmetics, soap and various products. Exposure to Triclosan creates a disruption between reactive oxygen species (ROS) and antioxidant defenses. Oxymatrine $[\mathrm{OMT}]$ has potent anti-cancer, anti-fibrosis, and anti-oxidant effects. Aim of work: To study the effect of Oxymatrine on Triclosan-induced ovarian toxicity. Material and Methods: The studied rats have been divided into five groups for measurement of total antioxidant capacity, Caspase-3, the levels of Tumor Necrosis Factor-alpha[TNF- $\alpha$ ], Estrogen and Progesterone levels, and Liposaccharide Binding Protein [LBP] gene expression in response to Triclosan-induced ovarian toxicity by realtime Polymerase Chain Reaction [PCR]. Results: Triclolsan [TCS] caused statistically significant reduction in total antioxidant capacity, with statistically significant elevation in TNF- $\alpha$ and Caspase- 3 activity compared to the control group. Oxymatrine induced statistically significant elevation in total antioxidant capacity, statistically significant decrease in the level of TNF- $\alpha$, Caspase-3 activity with increased levels of Estrogen and Progesterone compared to the Triclosan group. Histopathological and electron microscope examination revealed vacuolar degeneration and atretic follicles in rats treated with Triclosan, and significant improvement after Oxymatrine intake. In the Triclolsan + Oxymatrine [TCS+OMT] group, gene expression levels of TNF- $\alpha$, Caspase 3, Mitogen-activated protein kinase [MAPK], Nuclear Factor-kappa [NF-KB],
\end{abstract}


and Liposaccharide Binding Protein [LBP] were statistically significant reduced compared to the Triclolsan group. Conclusion: The use of Oxymatrine [OMT] as anti-oxidant lead to decrease in genetic expression of Tumor Necrosis Factor -alpha [TNF- $\alpha$ ], Caspase 3, p38-MAPK, [NF-KB], and LBP, in Triclosan-induced ovarian injuries.

Keywords: Triclosan, Ovary, Oxidative stress, Oxymatrine and TNF- $\alpha$ /MAPK/Caspase-3 pathway.

\section{Introduction}

Triclosan (TCS) is a xenoestrogen, broad-spectrum anti-bacterial generally found in personal care and sanitizing products, such as soaps, toothpaste, hair products and numerous cosmetic products [Alfhili and Lee, 2019]. The widespread use of Triclosan and its presence in human urine, milk and serum have increased concerns about its close association with various serious health disorders that may affect the development of cancer [Dinwiddie et al.,2014]. Although the Food and Drug Administration [FDA] banned TCS in September 2016, it is still a soap component, and still used in other personal care products at high concentrations [ Weatherly and Gosse, 2017].

Triclosan is described as a poor potential endocrine disruptor as it has been discovered to bind the androgen and estrogen receptors with agonistic and antagonistic effects [Kim et al., 2019]. Large evidence revealed that thyroid hormones is decreased by TCS in female rats [Fang et al., 2015].
Exposure to Triclosan creates a disruption between reactive oxygen species (ROS) and antioxidant defenses. Malondialdehyde is a product of lipid peroxidation that can be used to measure lipid oxidative damage [Wang et al.,2017]. TCS resulted in a disturbance in the livers of goldfish between oxidants and antioxidants, causing DNA damage [Wang et al., 2014]. Triclosan also increase in oxidative stress markers such as Gutathione S transferase [GST] activity [Han et al., 2016].

In the last few years, the incidence of human infertility has been elevated considerably worldwide. This may be attributed to genetic mutations. In the same way, many artificial chemicals, such as plastics, perfumed soaps, shampoo, toothpaste, and liquid disinfectants are widely used and could have a negative impact on human fertility [ Zhang et al., 2014].Exposure to Estrogenlike compounds and xenoestrogen has disrupted ovarian cycling in adult females [Venegas et al., 2019].

Oxymatrine [OMT] has potent 
anti-oxidative and anti-cancer effects [Wen et al., 2014] . By downregulating the Toll-like receptor [TLR] 4/nuclear factor $[\mathrm{NF}-\mathrm{kB}]$ in macrophages, Oxymatrine inhibits the inflammatory effect of lipopolysaccharide [LPS] [Zhang et al., 2014]. Inhibition of the Nuclear Factor-kappa [NF-KB] and Mitogen-Activated Protein Kinase [ MAPK] signaling pathway is consistent with the anti-inflammatory effects of OMT [Yang et al., 2014].

\section{Aim of work}

To study the effect of Oxymatrine on Triclosan-induced ovarian toxicity.

\section{Materials and Methods}

Study design: It is an experimental study.

Place and duration of the study: The study was conducted at the Department of Pharmacology, Faculty of Medicine, Benha University; from February 2017 to August 2018.

Study sample: Forty female adult Sprague Dawley rats were obtained from Helwan -breeding house, Cairo and their weight was 150-200 g. They have been caged in a well-ventilated place, $8 /$ cage at room temperature in the animal house. They were given free water and standard food for 7 days for acclimatization. The animals were treated according to the protocol of handling.

Study method: Rats were divided into five matching weight groups of eight animals, each as the following: Group 1: Normal control. Group 2: Corn oil-treated [as a diluent] [Cao et al., 2018]. Group 3: Triclosan (TCS) treated only. TCS was dissolved in dimethyl sulfoxide [DMSO], diluted with corn oil with DMSO concentration $0.5 \%$. After 3 or 4 regular estrous cycles, the rats were given the TCS orally at doses of $100 \mathrm{mg} / \mathrm{kg}$ per day at 08:00 h for 15 days [Cao et al., 2018]. Group 4: Oxymatrine treated only [50 $\mathrm{mg} / \mathrm{kg}$. The rats were intragastrically administered oxymatrine for 15 days [Zhang et al., 2017]. Group 5: Triclosan+ Oxymatrine treated.

-Drugs and chemicals: Triclosan [99.7\%] was bought in powder form from Sigma Aldrich [USA] CAT No. 3380-34-5, and Oxymatrine [National Food and Drug Control Institute, Lot 201508] was used. Using the enzymelinked immunosorbent assay, Estrogen and Progesterone levels were measured. ELISA Kits were purchased according to the protocol of manufacturers [Bioassay, Cat. No. E0259Mo and cat. No. E0243Mo, China]. The kits used 
for gene expression were purchased [Cat No:74104, Cat NO:18090019, and Cat NO:4309155] from Qiagen, Germany. Just before use, Triclosan and Oxymatrine were freshly prepared.

All rats were then fixed on the operating table and the blood samples were taken by the method defined by Parasuraman et al. [2010] from the heart. Blood samples were incubated at $37^{\circ} \mathrm{C}$ until the blood was clotted and then centrifuged for serum separation at 3000 revolutions per minute [rpm] for 15 minutes, which was preserved at $-20^{\circ} \mathrm{C}$ in order to evaluate the biochemical parameters.

- Tissue samples [0.5 g] were collected from each animal's both ovaries. They were washed in saline and used to prepare tissue homogenates, and then these samples were centrifuged in order to obtain sample supernatants.

-Determination of oxidative stress markers: To evaluate of oxidative stress markers, the supernatant obtained by centrifugation of $20 \%$ homogenate was used. Lipid peroxidation was measured by estimating the level of the lipid peroxidation decomposition product which is the reactive thiobarbituric acid as malondialdehyde [MDA] [Tsikas, 2017]. The findings have been expressed as $\mathrm{nmol} / \mathrm{g}$ of wet tissue. Using the commercial kit [Biodiagnostic, Cairo, Egypt], reduced glutathione was evaluated.

-Determination of Total Antioxidant Capacity [mmol/l]: Total serum antioxidant capacity was evaluated according to the Benzie and Strain [1999] method. The total antioxidant capacity was measured and expressed as $\mathrm{mmol} / \mathrm{L}$.

-Measurement of serum levels of TNF- $\alpha$ using enzyme-linked immune sorbent assay: [ELISA] by kits that are commercially available as instructed by the manufacturer [Quantikine HS; R\&D Systems, Minneapolis, MN, USA]. By ELISA reader, the intensity of enzymatic reaction was measured at a wavelength of $450 \mathrm{~nm}$.

-Caspase-3 concentration measurement: Quantitative determination of tissue Caspase-3 was evaluated using Caspase-3 Colorimetric Assay Kit [CASP-3-C] Sigma-Aldrich, Inc. directed by the manufacturer [Pradeep and Jänicke, 2016].

-Measurement of Estrogen and Progesterone: Serum levels of estrogen and progesterone hormones were measured using spectrophotometry as directed by the manufacturer [Mouse 
Estrogen ELISA Package, Bioassay, Cat. no. E0243Mo, China] and [ELISA Kit Mouse Progesterone, Bioassay, Cat., no. China, E0259Mo]. In the samples, Estrogen and Progesterone levels were determined from standard curves and expressed as ng/l. The methods of spectrophotometry were carried out by the ELISA Reader [ELX800, BioTek Company] for biochemical evaluation.

-Histo-pathological examination: Rats used in the experimental study were anaesthetized by intraperitoneal chloral hydrate injection [400 mg/ $\mathrm{kg}$ ]. In Bouin's fluid, both ovaries were dissected and fixed. Via a graded sequence of alcohol, the samples were dehydrated, cleared with xylene, and then embedded in paraffin wax. The sections were stained with Hematoxylin and Eosin [H\&E] after the $5 \mu \mathrm{m}$ sections were deparaffined and rehydrated [Winship et al., 2020] and examined under the light microscopic.

- Electron microscopic examination: Survey sections were cut using an ultramicrotome; one micron thick [semithin section], with glass knives then stained with toluidine blue. Examination was done at 80 kilovolts, the stained sections were investigated by a transmission electron microscope. At Tanta University electron microscope unit, photographs were taken, produced, printed, and examined.

-Determination of TNF $\alpha$, Caspase 3, NF$\kappa \mathrm{B}$, LBP andp38-MAPK gene expression level by real-time PCR: The total RNA was extracted from ovarian tissues by the RNeasy Mini pack [Qiagen, Germany]. Nanodrop [Biowave II Germany] was used to check the purity and concentration of RNA spectrophotometrically at 260 and $280 \mathrm{~nm}$. Complementary DNA [cDNA] has been synthesized according to the manufacturer's instructions using Superscript Choice systems [Life Technologies, USA]. Quantitative real-time PCR was performed using SYBR Green PCR Master Mix [Applied Biosystems, CA, USA] as described by the manufacturer in a $25 \mathrm{ml}$ reaction volume. PCR reactions include $10 \mathrm{sec}$ at $95^{\circ} \mathrm{C}, 30 \mathrm{sec}$ at $55^{\circ} \mathrm{C}$, $1 \mathrm{~min}$ at $55^{\circ} \mathrm{C}$ using Rotorgene real-time PCR system [Qiagen- S.Korea]. The expression level was calculated from the PCR cycle threshold [CT]. Data analysis was performed using the comparative $\mathrm{CT}\left[2^{-\Delta \Delta \mathrm{CT}}\right]$ method with normalization to glyceraldehyde-3-phosphate dehydrogenase [GAPDH] expression [Livak and Schmittgen, 2001]. The GAPDH mRNA level was detected as an internal control for normalization [reference gene]. PCR primers sequencesare:TNF $\alpha$ :For5'CAATGGCATG GATCTCAAAG3', Reverse 5'CAGAGCAA TGACTCCAAAGT3'Casp3 forward5'ATG GACAACAACGAAACCTCCGTG3'Rever 
se 5'CCACTCCCAGTCATTCCTTTAGTG3' LBP : forward 5'ACTACAGTTTGGTGGCG3' , R e vers e $5^{\prime}$ T T G T T G A A A G T TA TTGAGGC3'NF-kB [p65] : forward 5'TGATGTGCATCAAGTGG3'Reverse 5'GAAGTTGAGTTTCGGGTAGGC3'p 38,MAPK:forward 5'CGTTGTTTCCTG GTACAGACC3Reverse5'CCATTTCTI CTTGGTCAAGGG3'GAPDH:forward5 'CCCATCACCATCT TCCAGGAGC3' Reverse5'CCAGTGAGCTTCCCGTTCAGC 3'

\section{Consent}

Not applicable

\section{Ethical approval}

The protocol of the study was approved by Ethical Committee
Board of Faculty of Medicine, Benha University. The number of acceptance is 20207308 .

\section{Data management}

The obtained results were tabulated as mean and standard deviation [Mean $\pm \mathrm{SD}]$. A one-way variance analysis [ANOVA] was used to detect all important variations between the mean groups. Then, t-test was used to detect the differences between the studied groups. Probability values $[\mathrm{p}]<0.05$ have been defined as a statistically significant result. For non-parametric parameters, the Kruskal Wallis test and Dunn post hoc were used.

\section{Discussion}

\section{Results}

Table 1: The effect of administration of Oxymatrine on Total antioxidant capacity, Glutathione (GSH) and Malondialdehyde [MDA] on Triclosan-induced ovarian toxicity in rat models.

\begin{tabular}{|c|c|c|c|}
\hline & $\begin{array}{l}\text { Total antioxidant } \\
\text { capacity }[\mathrm{mmol} / \mathrm{l}] \\
\text { Mean } \pm \mathrm{SD}\end{array}$ & $\begin{array}{c}\text { GSH }[\mu \mathrm{mol} / \mathrm{g} \text { tissue }] \\
\text { Mean } \pm \text { SD }\end{array}$ & $\begin{array}{c}\text { MDA }[\mu \mathrm{mol} / \text { gtissue }] \\
\text { Mean } \pm \text { SD }\end{array}$ \\
\hline Control & $96.82 \pm 0.03$ & $4.85 \pm 0.17$ & $20.92 \pm 0.68$ \\
\hline Corn oil treated & $92.34 \pm 0.14$ & $4.71 \pm 0.19$ & $19.14 \pm 0.43$ \\
\hline TCS treated & $25 \pm 0.1^{\mathrm{a}, \mathrm{c}, \mathrm{d}}$ & $2.81 \pm 0.22^{\mathrm{a}, \mathrm{c}, \mathrm{d}}$ & $37.35 \pm 1.5^{\mathrm{a}, \mathrm{c}, \mathrm{d}}$ \\
\hline OMT treated & $94.85 \pm 0.17$ & $5.1 \pm 0.13$ & $20.11 \pm 0.91$ \\
\hline TCS + OMT & $71.33 \pm 0.21^{\mathrm{a}, \mathrm{b}, \mathrm{c}, \mathrm{d}}$ & $3.6 \pm 0.2^{\mathrm{a}, \mathrm{b}, \mathrm{c}, \mathrm{d}}$ & $22.4 \pm 0.9^{\mathrm{b}}$ \\
\hline
\end{tabular}

GSH: Glutathione. MDA: Malondialdehyde . TCS: Triclosan. OMT: Oxymatrine. a: Significant compared to control group at $p>0.05 \quad$ b: Significant compared to TCS treated group at $p>0.05 \quad$ c: Significant compared to corn oil treated group at $p>0.05$ d: Significant compared to OMT treated group at $\mathrm{p}>0.05$. 
Table 1: showed that induction of Triclosan to rat's model lead to significant decrease in total antioxidant capacity, GSH levels and a significant elevation in MDA levels in compared to the control group. There was a significant increase in both Total antioxidant capacity, Glutathione [GSH] and MDA level when the rats received Oxymatrine and also in (TCS+OMT) rat's model.

Table 2: The effect of administration of Oxymatrine on TNF- $\alpha$, Caspase-3, Estrogen and Progesterone on Triclosan-induced ovarian toxicity in rat models.

\begin{tabular}{|l|c|c|c|c|}
\hline & $\begin{array}{c}\text { TNF- } \alpha \text { [pg/ml] } \\
\text { Mean } \pm \text { SD }\end{array}$ & $\begin{array}{c}\text { Caspase3[Pg/ } \\
\text { ml] } \\
\text { Mean } \pm \text { SD }\end{array}$ & $\begin{array}{c}\text { Estrogen[ng/l] } \\
\text { Mean } \pm \text { SD }\end{array}$ & $\begin{array}{c}\text { Progesterone[ng/l] } \\
\text { Mean } \pm \text { SD }\end{array}$ \\
\hline Control & $81.54 \pm 11.4$ & $0.66 \pm 0.02$ & $13.5 \pm 0.55$ & $8.49 \pm 0.94$ \\
\hline Corn oil treated & $82.34 \pm 7.4$ & $0.82 \pm 0.04$ & $13.11 \pm 0.34$ & $8.66 \pm 0.32$ \\
\hline TCS treated & $389.11 \pm 19.6^{\mathrm{a}, \mathrm{c}, \mathrm{d}}$ & $11.1 \pm 1.4^{\mathrm{a}, \mathrm{c}, \mathrm{d}}$ & $5.15 \pm 1.1^{\mathrm{a}, \mathrm{c}, \mathrm{d}}$ & $1.42 \pm 0.17^{\mathrm{a}, \mathrm{c}, \mathrm{d}}$ \\
\hline OMT treated & $81.35 \pm 8.1$ & $0.62 \pm 0.03$ & $12.91 \pm 0.56$ & $8.31 \pm 0.24$ \\
\hline TCS+OMT & $114.2 \pm 11.1^{\mathrm{a}, \mathrm{b}, \mathrm{c}, \mathrm{d}}$ & $2.8 \pm 0.16^{\mathrm{a} . \mathrm{b} . \mathrm{c}, \mathrm{d}}$ & $8.436 \pm 1.43^{\mathrm{a}, \mathrm{b}, \mathrm{c}, \mathrm{d}}$ & $4.78 \pm 0.97^{\mathrm{a}, \mathrm{b}, \mathrm{c}, \mathrm{d}}$ \\
\hline
\end{tabular}

TNF- $\alpha$ : Tumor Necrosis Factor -alfa. TCS: Triclosan.

OMT: Oxymatrine.

a: Significant compared to control group at $p>0.05$ b: Significant compared toTCS treated group at $p>0.05$ c: Significant compared to corn oil treated group at $p>0.05$ d: Significant compared to OMT treated group at $\mathrm{p}>0.05$.

Table 2 showed that induction of Triclosan to rat's model leads to significant increase in the level of TNF- $\alpha$, increased activity of Caspase- 3 and reduced levels of Estrogen and Progesterone compared to the control group, a significant decrease in levels of Tumor necrosis factor- alpha [TNF- $\alpha$ ], decreased Caspase-3 activity with increased Estrogen and Progesterone levels when the rats received Oxymatrine and also in (TCS+OMT) rat's model.

Histopathological study: On studying the specimen under the light microscope; it was evident that Groups 1,2,4 had normal follicles and normal corpus luteum, while group 3 [treated with Triclosan only] showed: 30\% atretic follicles, 30\% 
hyperplasia of corpus luteum, 10\% atretic follicles and corpus luteum hyperplasia, $30 \%$ vacuolar degeneration. A 50\% improvement in the follicular cells was seen in group 5 treated with Triclosan and Oxymatrine.

Electron microscopic study: In group 3 [treated with Triclosan only] there were $30 \%$ atretic follicles, $50 \%$ abnormal corpus luteum with increased droplets and irregular lipids in the nucleus, and $20 \%$ follicular degeneration. Group 1, 2, 4 had a normal follicle with a normal corpus luteum. In group 5, (rats treated with Triclosan and Oxymatrine) showed a 50\% improvement with minor degenerative changes in follicular cells.

\section{Figure 1: Histopathological examination of the studied rat's}

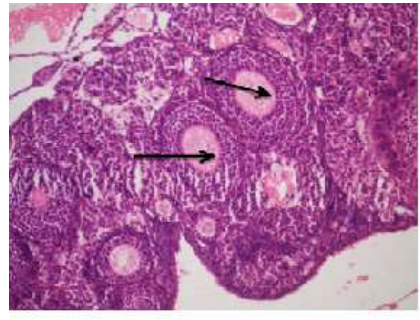

$1 \mathrm{~A}$

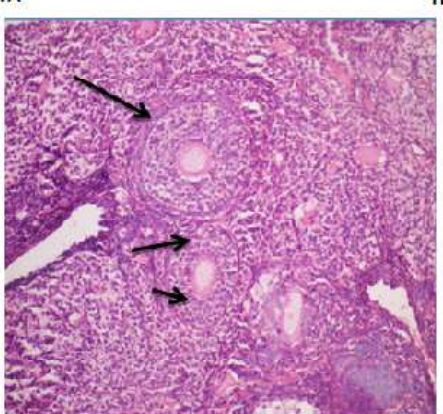

1D

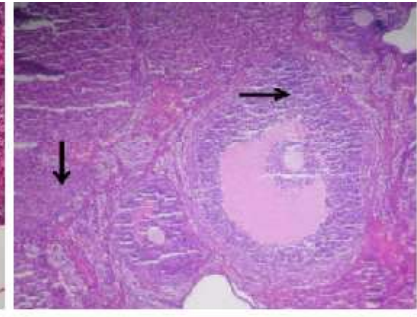

1B

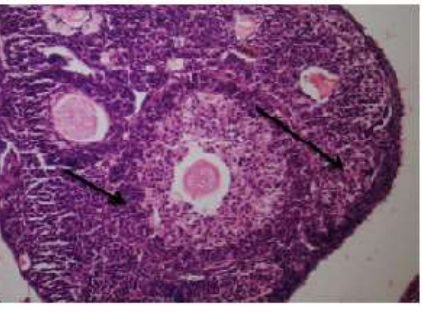

1C

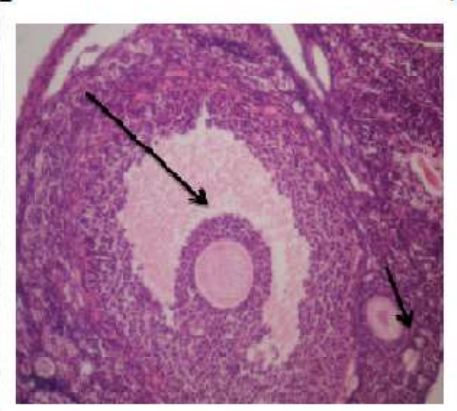

$1 E$

Histo-pathological examination of a section in rat's ovary prepared from a control rat [ $1 \mathrm{D}]$ and in rat's ovary prepared from corn oil group rat [1 E] showing normal architecture with a well-arranged primary follicle [arrows]. The section prepared from Oxymatrine group rat [1A] showing normal architecture with a wellarranged primary follicle [arrow] while there is vacuolar degeneration [arrow] and atretic follicles in Triclosan treated rat [1B] and some improvement in the follicular cell in Oxymatrine and Triclosan group [1 C] [arrow] [Hx\& E x100]. 
Figure 2: Electron microscopic examination of the studied rat's ovary :

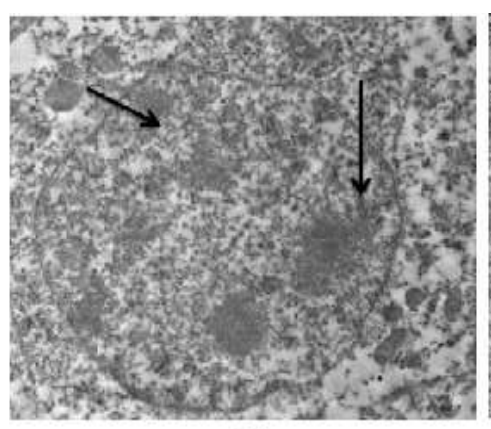

$2 \mathrm{~A}$

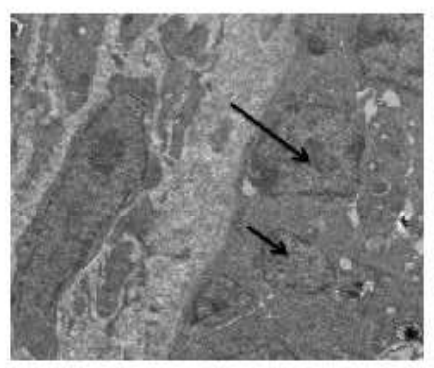

$2 \mathrm{D}$

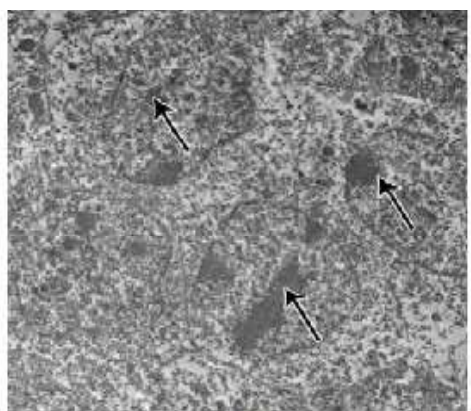

2B

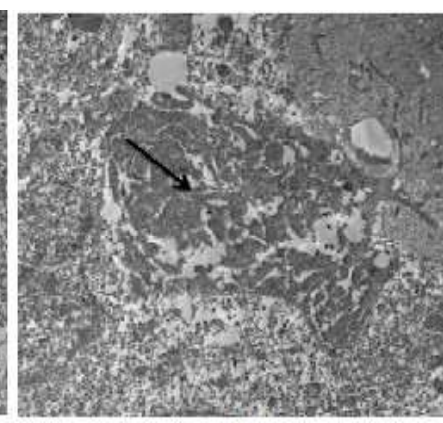

$2 \mathrm{C}$

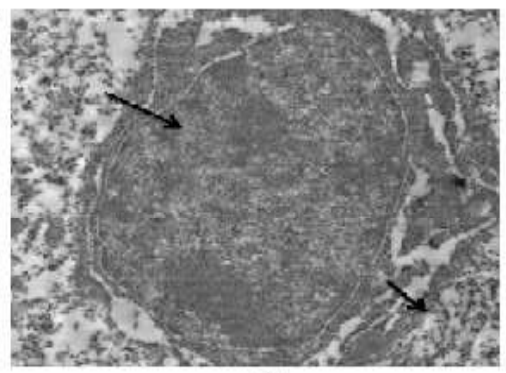

$2 E$

Electron microscopic examination of rat's ovary prepared from a control rat [2A], corn oil group rat[2B] showed primary follicles [arrow] with normal architecture while electron micrograph from Triclosan treated group [2C] showed follicular degeneration and vacuolation with nucleus rarefaction [follicular atresia]. The section prepared from Oxymatrine group rat [2D] showed normal follicular cells with a regular nucleus [arrows]. Micrograph of rat's ovary prepared from Triclosan and Oxymatrine group [2E] showed some improvement in the follicular cell in Fig 2E due to Oxymatrine's antioxidant action. 
Figure 3: Effects of Triclosan and Oxymatrine on Tumor Necrosis Factoralpha [TNF- $\alpha$ ], Caspase 3, P38- -Mitogen-Activated Protein kinase [MAPK], Nuclear Factor- KB [NF-KB] and Liposaccharide Binding Protein [LBP] mRNA expression in rat's ovarian tissues:

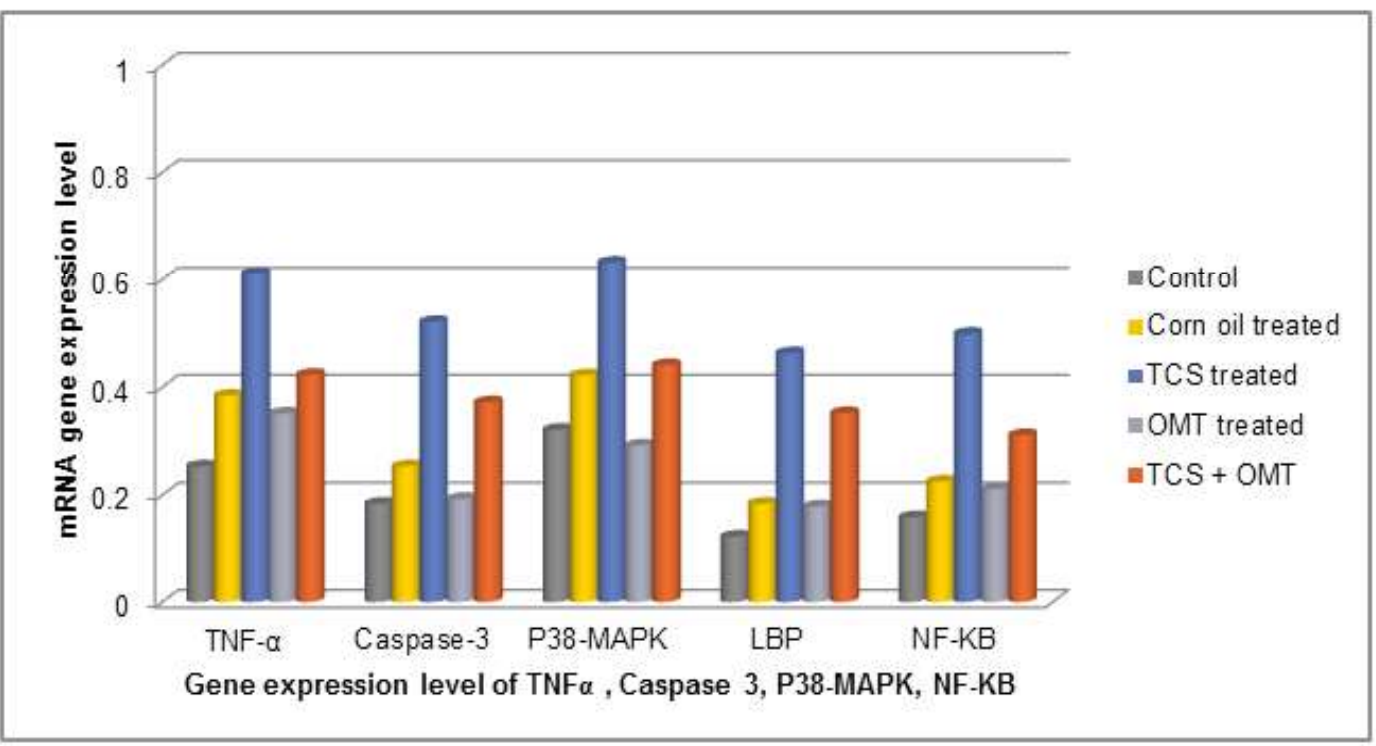

PCR results were quantified; RNA expression levels are presented as bar graphs relative to the internal control Glyceraldehyde 3-Phosphate Dehydrogenase [GAPDH].

Figure 3 showed that the effect of Triclosan and Oxymatrine on gene expression of TNF- $\alpha$, Caspase 3, p38-MAPK, NF-KB, and LBP by RT-PCR: mRNA expression levels of TNF-alpha, Caspase 3, Mitogen Activated Protein kinase [p38-MAPK], Nuclear factor-kappa [NF-KB] and LBP were more or less approximate to OMT and control groups. However, in the TCS treated group, their genetic expressions were significantly increased. In the [TCS + OMT] group, mRNA expression levels of TNF- $\alpha$, Caspase 3, p38-MAPK, NF-KB, and LBP were significantly reduced compared to the TCS group. 
Recently, several chemicals have been shown to cause endocrine system disruption in humans. They are named endocrine-disrupting chemicals [EDCs] such as Triclosan (TCS) and bisphenol $A$ and the association between Triclosan(TCS) exposure and female infertility remains unclear [Paoli et al., 2020].

The current study showed that TCS resulted in statistically significantly decrease in the levels of Glutathione [GSH] and Total antioxidant capacity compared to the control rats, with statistically significant increase in the MDA level (Table 1). These results are in accordance with Movahed et al [2016] in their work on the effect of Triclosan on Cryptococcus neoformans

The findings of the present study showed that Triclosan with increased Caspase-3 activity induces a substantial increase in the TNF- $\alpha$ (Table 2). Yang and his colleagues in 2018 in their work on a common antimicrobial additive increases colonic inflammation and colitis-associated colon tumorigenesis in mice reported that TCS exposure has also been shown to cause an increase in colon cancer in a mouse colorectal cancer model. The mechanisms involved an increased plasma TNF- $\alpha$ and interleukin-6, with their genetic expression which showed a high elevation in colon tumors

The current work showed that Triclosan administration induces a significant decrease in both Estrogen and Progesterone levels (Table 2). Our findings were similar to that obtained by Cao, et al.[2018] in their study on impact of Triclosan on female reproduction in mice and reported that Triclosan reduces estradiol and estrone sulfonation acting as an Estrogen receptor antagonist. Furthermore, Yuan et al., 2015 indicated that pre-implantation exposure to TCS could also cause failure of embryo implantation in mice. Also, TCS exposure can alter the expression of the Estrogen and Progesterone receptors in the uterus of rats [Berger et al., 2010].

Compared to the Triclosan treated group, when Oxymatrine was given there was a statistically significant increase in both Total antioxidant capacity and Glutathione [GSH] with MDA level normalization (Table 1). Oxymatrine also induces a substantial decrease in TNF- $\alpha$ levels, reduced activity of Caspase- 3 and increased levels of Estrogen and Progesterone (Table 2). 
Oxymatrine has antiviral, antiinflammatory, and anti-tumor effects [Wang et al., 2011]. By promoting collagenase-mediated tissue degradation, TNF- $\alpha$ plays a significant role in periodontal tissue destruction. Serum TNF- $\alpha$, IL-1 $\beta$, and prostaglandin E2 [PGE2] were substantially reduced by Oxymatrine treatment. This indicates that Oxymatrine can prevent inflammatory factors from being secreted [Liao et al., 2014].

Several studies explained the protective effect of Oxymatrine against oxidative damage by its role in activating Nuclear Factor -2 [Nrf2] / heme-oxygenase-1 [HO-1] signaling pathway which is evident by the work done by Li and his colleagues 2017, in their study on the protective effects of Oxymatrine against arsenic trioxideinduced liver injury, and Liu et al., 2020 in their study on Oxymatrine protects neonatal rat against hypoxic-ischemic brain damage. Oxymatrine also protected against experimental hepatic fibrosis [Song et al., 2019]. In addition, Oxymatrine was found to prevent adriamycin-induced heart damage in rabbits, which was associated with its antioxidant and anti-apoptotic activities [Runtao et al., 2011].
The findings of the current study denote that Oxymatrine had an antioxidant effects; theimprovement in the levels of Estrogen and Progesterone could be due to the above effects of Oxymatrine.

Cao et al. [2018] found that histopathological changes due to the effect of TCS on the ovaries were follicular degeneration, vacuolation, and increase in atretic follicles, which was in accordance with the result of the present study as shown in Fig(1).

Also electron microscopic study of the same ovaries (exposed to Triclosan) showed follicular atresia (Fig (2)). Similar results were observed by Michael et al. (2017) in their work on female frogs as they detected follicular atresia and mononuclear cell infiltrates.

According to the results of the present study, Oxymatrine could have a protective effect on Triclosan-induced ovarian toxicity, the mRNA expression levels of TNF- $\alpha$, Caspase 3, p38MAPK, NF-KB, and LBP were found to be approximate in OMT and control groups. However, their expression levels were significantly increased in the TCS treated group. In the TCS + OMT group, mRNA expression levels of TNF- $\alpha$, Caspase 3, p38-MAPK, 
NF-KB, and LBP were significantly reduced in comparison with TCS group (Fig 3). Similar results were detected by Zhang et al., 2016 who found that Triclosan markedly disrupted the ovarian structure and function, and the underlying mechanism can be due to the activation of Liposaccharide Binding Protein [LBP] by toxins, such as Lipopolysaccharide [LPS]. NF-KB and p65 signaling pathway activation can result in increased TNF- $\alpha$ and activation of the p38 MAPK/Caspase 3 inducing pathway ovarian cell apoptosis.

According to our knowledge, this study is the first one to report that Triclosan-induced ovarian injuries may be correlated with the signaling pathway of TNF- $\alpha / \mathrm{p} 38 \mathrm{MAPK} /$ Caspase 3 , and that OMT as an antioxidant may suppress these injurious effects.

\section{Conclusion}

Being a potential endocrine disrupter, several studies have recorded the harmful effects of Triclosan on the ovary. In a trial to overcome these adverse effects, the current study showed that Oxymatrine can be used to minimize these effects, and we found that Oxymatrine can improve Triclosan-induced ovarian injuries via suppression of mRNA expression levels of TNF- $\alpha$, Caspase 3, p38-MAPK, NF$\mathrm{KB}$ and LBP.

\section{Conflict of interest}

The authors declared that there is no conflict of interest.

\section{Funding}

No particular grants from funding agencies in the public, commercial or non-profit sectors were obtained for this study.

\section{Acknowledgment}

Authors are thankful to technical and administrative staff at the departments of Pharmacology, Pathology, Biochemistry and Clinical Pathology, Faculty of Medicine, Benha University, Egypt for their support during the study.

\section{References}

1- Alfhili MA and Lee MH (2019): Triclosan: An Update on Biochemical and Molecular Mechanisms. J of Oxid Med Cell Longev ;Article ID 1607304, 28 pages. https://doi. org/10.1155/2019/1607304.

2-Benzie IFF and Strain JJ( 1999) : Reducing/ antioxidant power assay: direct measure of total antioxidant activity of biological fluids and modified version for simultaneous measurement of total antioxidant power and ascorbic acid concentrationIn: Methods in enzymology. Elsevier; 299:15-27. https://doi.org/10.1016/ S0076-6879(99)99005-5

3-Berger RG, Foster WG, and deCatanzaro D (2010):Bisphenol-A exposure during the 
period of blastocyst implantation alters uterine morphology and perturbs measures of estrogen and progesterone receptor expression in mice. ReprodToxicol;30[3]:393-400. doi: 10.1016/j. reprotox.2010.06.006

4-Cao XY, Hua X, Xiong J-W, Zhu W-T, Zhang J, et al.(2018): Impact of Triclosan on Female Reproduction through Reducing Thyroid Hormones to Suppress Hypothalamic Kisspeptin Neurons in Mice. Front Mol Neurosci;19(11):6. https://doi.org/10.3389/ fnmol.2018.00006

5-Dinwiddie MT, Terry PD and Chen J (2014): Recent evidence regarding triclosan and cancer risk. Int J Environ Res Public Health; 11[2]:2209-17. doi: 10.3390/ijerph110202209.

6-Fang JL, Vanlandingham MM, Juliar BE, Olson GR, Patton RE, et al.(2015) :Dose-response assessment of the dermal toxicity of Triclosan in B6C3F1 mice. Toxicol Res [Camb];4[4]:86777. https://doi.org/10.1039/C4TX00152D

7-Han J, Won EJ, Hwang UK, Kim IC, Yim JH, et al. (2016): Triclosan [TCS] and Triclocarban [TCC] cause lifespan reduction and reproductive impairment through oxidative stress-mediated expression of the defensome in the monogonont rotifer [Brachionus koreanus]. Comp Biochem Physiol Part C Toxicol Pharmacol;185:131-7. doi: 10.1016/j.cbpc.2016.04.002.

8-Kim S, Lee S, Shin C, Lee J, Kim S, et al. (2018): Urinary parabens and triclosan concentrations and associated exposure characteristics in a Korean population-A comparison between night-time and first-morning urine. Int $\mathrm{J}$ Hyg Environ Health ;221 [4]:632 - 41. doi: 10.1016/j. ijheh.2018.03.009.

9-Liao CH, Fei W, Shen ZH, Yin MP, Lu C, et al. (2014): Expression and distribution of TNF- $\alpha$ and PGE2 of periodontal tissues in rat periodontitis model. Asian Pac J Trop Med ;1,7(5):412-6. doi: 10.1016/S19957645(14)60067-5.
10-Li L, Liu Q, Fan L, Xiao W, Zhao L, et al.( 2017): Protective effects of oxymatrine against arsenic trioxide-induced liver injury. Oncotarget;8[8]:12792-9. https://doi. org/10.18632/oncotarget.12478.

11-Liu Y, Wang H, Liu N, Du J, Lan X, et al. (2020): Oxymatrine protects neonatal rat against hypoxic-ischemic brain damage via PI3K/Akt/ GSK3 $\beta$ pathway. J Life sci;254:116444. doi: 10.1016/j.1fs.2019.04.070.

12-Livak KJ and Schmittgen TD ( $₹ \ldots 1)$ : Analysis of relative gene expression data using real-time quantitative PCR and the $2-\Delta \Delta \mathrm{CT}$. Method ;25[4]:402 - 8. doi: 10.1006/meth.2001.1262. Available at : http://www.gene-quantification. net/livak-2001.pdf

13- Mathis MB , Pawlowski S, Wolf JC, Peter R ,Champ S, et al.(2017): Effect of triclosan on anuran development and growth in a larval amphibian growth and development assay. J Appl Toxicol ;37: 1182-94. https://doi. org/10.1002/jat.3474

14-Movahed E, Tan GMY, Munusamy K, Yeow TC, Tay ST, et al. (2016) :Triclosan demonstrates synergic effect with amphotericin B and fluconazole and induces apoptosis-like cell death in Cryptococcus neoformans. Front Microbiol;7:360. https://doi.org/10.3389/ fmicb.2016.00360.

15-Paoli D, Pallotti F, Dima AP, Albani E, Alviggi C, et al. (2020): Phthalates and Bisphenol A: Presence in Blood Serum and Follicular Fluid of Italian Women Undergoing Assisted Reproduction Techniques. Toxics;8[4]:91.doi: 10.3390/toxics8040091.

16-Parasuraman S, Raveendran R, and Kesavan $R$ ( 2010): Blood sample collection in small laboratory animals. J Pharmacol Pharmacother;1[2]:87-93. doi: 10.4103/0976$500 X .72350$.

17-Pradeep AR, Suke DK, Prasad MR, Singh SP, Martande SS, et al.,(2016): Expression 
of key executioner of apoptosis caspase 3 in periodontal health and disease. J Investig Clin Dent; 7[2]:174-9. doi: 10.1111/jicd.12134

18-Runtao G, Guo D, Jiangbo Y, Xu W, Shusen $Y$,et al. (2011): Oxymatrine, the main alkaloid component of Sophora roots, protects heart against arrhythmias in rats. Planta Med;77[03]:226-30. doi: $10.1155 / 2017 / 4615727$

19-Sinha R, Sharma TR and Singh AK (2019): Validation of reference genes for qRT-PCR data normalisation in lentil (Lens culinaris) under leaf developmental stages and abiotic stresses. Physiol Mol Biol Plants; 15;25[1]:123-34. https://doi.org/10.1007/s12298-018-0609-1

20-Song LY, Ma YT, Fang WJ, He Y, Wu JL, et al. (2019): Inhibitory effects of oxymatrine on hepatic stellate cells activation through TGF- $\beta /$ miR-195/Smad signaling pathway. BMC Compl Alternative Med;19[1]:138. doi: 10.1186/ s12906-019-2560-2.

21-Tsikas D (2017): Assessment of lipid peroxidation by measuring malondialdehyde (MDA) and relatives in biological samples: Analytical and biological challenges. Anal Biochem; 1(524):13-30. doi: 10.1016/j.ab.2016.10.021.

22-Venegas B, Gordillo LY, Rosas G, Espinoza JA, Morán C, et al. (2019): In rats with estradiol valerate-induced polycystic ovary syndrome, the acute blockade of ovarian $\beta$-adrenoreceptors improve ovulation. Reprod. Biol. Endocrinol;17[1]:1-0. https://doi. org/10.1186/s12958-019-0539-y

23-Wang F, Li C, Liu W, and Jin Y (2014): Potential mechanisms of neurobehavioral disturbances in mice caused by sub-chronic exposure to lowdose VOCs. Inhal Toxicol;26[4]:250-8. https:// doi.org/10.3109/08958378.2014.882447.

24-Wang F, Xu R, Zheng F, and Liu H (2017): Effects of triclosan on acute toxicity, genetic toxicity and oxidative stress in goldfish [Carassius auratus]. Exp Anim;17-101. https://doi.org/10.

\section{9/08958378.2014.882447.}

25-Wang YP, Zhao W, Xue R, Zhou Z-X, Liu F, et al.( 2011): Oxymatrine inhibits hepatitis B infection with an advantage of overcoming drug-resistance. Antiviral Res;89[3]:227-31. https://doi.org/10.1016/j.antiviral.2011.01.005

26-Weatherly LM and Gosse JA (2017): Triclosan exposure, transformation, and human health effects. J Toxicol Environ Heal - Part B Crit Rev [Internet];20[8]:447-69. doi: 10.1080/10937404.2017.1399306

27-Wen JB, Zhu FQ, Chen WG, Jiang LP, Chen J, et al. (2014): Oxymatrine improves intestinal epithelial barrier function involving NF-kBmediated signaling pathway in $\mathrm{CCl} 4$-induced cirrhotic rats. PLoS One, 9[8]:e106082. https:// doi.org/10.1371/journal.pone.0106082.

28-Winship AL, Sarma UC, Alesi LR, and Hutt KJ (2020): Accurate Follicle Enumeration in Adult Mouse Ovaries. JoVE (Journal of Visualized Experiments); 16[164]:e61782. doi: $10.3791 / 61782$.

29-Yang H, Wang W, Romano KA, Gu M, Sanidad $\mathrm{KZ}$, et al. (2018): A common antimicrobial additive increases colonic inflammation and colitis-associated colon tumorigenesis in mice. Sci Transl Med;10[443]:eaan4116. doi: 10.1126/scitranslmed.aan4116.

30-Yuan M, Bai MZ, Huang XF, Zhang Y, Liu J, et al. (2015): Preimplantation exposure to bisphenol A and triclosan may lead to implantation failure in humans. Biomed Res Int;1; 2015:184845. doi: 10.1155/2015/184845.Available at: https:// pubmed.ncbi.nlm.nih.gov/26357649/

31-Zhang H, Wang S, Zhang S, Wang T, Deng $X$,et al. (2014): Increasing trend of prevalence of infertility in Beijing. Chin Med J [Engl];127[4]:691-5. doi: 10.3760/ cma.j.issn.0366-6999.20132698

32-Zhang M, Wang X, Bai B, Zhang R, Li Y, et al.(2016): Oxymatrine protects against sepsisinduced myocardial injury via inhibition of 
the TNF- $\alpha / \mathrm{p} 38-\mathrm{MAPK} /$ caspase-3 signaling pathway. Mol Med Rep;1;14[1]:551-9. doi: 10.3892/mmr.2016.5250.

33-Zhang YY,YiM, andHuang YP(2017):Oxymatrine ameliorates doxorubicin-induced cardiotoxicity in rats. Cell Physiol Biochem;43[2]:626-35. doi: $10.1159 / 000480471$. 